\title{
An Autoethnography of Fat and Weight Loss: Becoming the Bw0 with Deleuze and Guattari
}

\author{
by Valerie M Sheach Leith
}

\author{
The Robert Gordon University
}

Sociological Research Online, 21 (3), 7

$<$ http://www.socresonline.org.uk/21/3/7.html>

DOI: $10.5153 /$ sro.3971

Received: 28 Mar 2015 | Accepted: 26 Jun 2016 I Published: 31 Aug 2016

\begin{abstract}
This article experiments with some of the insights provided by the work of Deleuze and Guattari as a move towards deterritorializing fat bodies. This is necessary because in contemporary Western society the fat [female] body is positioned and frequently experienced as lacking in social, cultural and political value and as being in need of surveillance and control, not least by the neo-liberal 'self'. This article is a response to Deleuze and Guattari's plea to 'think differently', in this case about fat and weight loss. The article eschews the paradigmatic form of the traditional academic research paper, adopting a semi autoethnographic approach to present an analysis of my engagement with the Biggest Loser (diet) Club. Thinking through rather than about the body it focuses on embodied experiences of fat and the on-going process of cutting that body down to 'normal' size. By utilising two central concepts in Deleuzoguattarian thought 'becoming' and the 'body - without - organs' (BwO) - I seek to demonstrate the embodied, theoretical and ethical potential of utilising Deleuze and Guattari's work to explore fat and weight loss and how this might productively serve to deterritorialize contemporary discourses which stigmatise fat bodies.
\end{abstract}

Keywords: Becoming, BwO, Deleuze and Guatarri, Fat, Weight Loss, Autoethnography

\section{Introduction}

1.1 This article experiments with some of the insights provided by the work of the French philosophers Giles Deleuze and Felix Guattari as a move towards deterritorializing fat bodies. That is 'to free up the fixed relations that contain a body all the while exposing it to new organisations' (Parr 2010: 69). By utilising a Deleuzoguattarian analytical lens and autoethnographic writing to explore my own embodied experience of fat and weight loss, I seek to stimulate ways of thinking about fat and fat (female) bodies differently. Commencing with a consideration of how fat - and particularly fat female - bodies are currently lived, understood and connected with (thus illuminating how they are currently territorialized), I then move to situate the article within the contemporary critical obesity literature. The two key concepts which are utilised in this paper, becoming and the body without organs (BwO), are then outlined. This is followed by an account of my long term dissatisfaction with my weight and surprisingly enthusiastic engagement with the disciplinary practices embedded in a commercial weight loss programme, The Biggest Loser, an offshoot of the Channel Four reality programme. With the same goal of attempting to free the fat body from its fixed relations, in the next section, drawing specifically on the Deleuzoguattarian inspired work of Coleman (2008, 2011, 2013), I interrogate a specific aspect of my fat embodiment. Finally, in light of this cartography of a fat body becoming slim [mer], in the discussion section I aim to demonstrate the embodied, theoretical and ethical potential of utilising Deleuze and Guattari's work to explore embodied fat and weight loss assemblages and suggest that such efforts might ultimately assist in deterritorializing contemporary stigmatising discourses surrounding obesity.

\section{Monstrous Fat and Monstrous Women}

2.1 In seeking to open up (multiply) perceptions of fat and fat female bodies we must first consider how they are currently territorialized. Note, however, that in creating the concepts of territorialization and deterritorialization Deleuze \& Guattari (1987) are not suggesting that these flows exist independently of each other; but rather that 
they are simultaneously criss-crossing. Thus the outline of the territorialization of fat and fat female bodies below also contains (although unexpressed in this instance) the potential for its deterritorialization.

In contemporary Western society the fat body is positioned and frequently experienced as lacking in social, cultural and political value. Biomedical discourse ensnares the fat body in myriad calculations of risk in relation to morbidity and mortality, and this pervasive and persuasive power to define what bodies are ultimately renders fat bodies (as deviant and diseased) a major threat to the body politic. As Turner (2008: 100) states 'Because the body is the most potent metaphor of society, it is not surprising that disease is the most salient metaphor of structural crisis. All disease is disorder - metaphorically, literally, socially and politically'. Biopolitics, the politics of life itself (Rose 2001) thus seeks to discipline the corpulent carapace and the inner 'self' of the fat neoliberal subject. Fat citizens are called to account for their moral character with the failure to adhere to, achieve, or strive for a 'normal' weight leaving them open to the stigmatising charges of gluttony and sloth.

Fat as a stigmatising difference is, of course, juxtaposed with other forms of differentiation, notably class and gender. Whilst obesity is frequently constructed as a problem of the working classes, it is the behaviour of working class women that comes under greatest scrutiny (Skeggs 1997). How gender is implicated in obesity discourses becomes apparent when unpicking the role the body plays in producing gender. The male body and self is positioned as being one of containment and control: bounded in time and space, rational and autonomous and closed off from other bodies and the world (Grosz 1994; Shildrick 1997; Shildrick 2002). As Shildrick (2002: 50) argues, the legacy of Cartesian dualism means that 'To be a self is above all to be distinguished from the other, to be ordered and discrete, secure within the well-defined boundaries of the body rather than actually being the body' (emphasis in the original). In contrast, women are constructed as their (unbounded) bodies, liable to spill out of their fleshy containers and, as a result of their reproductive capacities, subject to bodily metamorphoses which threaten the imagined impermeable boundary between self and other and destabilise notions of a unified self (Braidotti 2002, 2011). Through an excess of materiality and emotion (Shildrick 1997) women are perceived as a threat to the social order and are seen to be controlled by, rather than being in control of their bodies. The liminal position of women is eloquently put by Braidotti (2011: 228), who writes, 'Woman/mother is monstrous by excess: she transcends established norms and transgresses boundaries. She is monstrous by lack: woman/mother does not possess the substantive unity of the masculine subject.'

2.4 When the materiality of the already problematised female form is further layered by fat, ambiguous tissue that is neither solid nor liquid but something in between, then the problematic nature of women's bodies is further exacerbated. Lupton (2012) argues that the fat body is positioned as a transgressive body; the fatfemale body is surely doubly so. Lacking 'respect [for] borders, positions, rules' (Kristeva 1982: 4) it is perceived and experienced as abject. Furthermore, neo-liberal discourses merging personal and maternal responsibility with concerns about an 'obesity epidemic' result in fat women being held responsible not only for their own disorder, but as largely culpable for the potential disorder of future generations (McNaughton 2011). They are thus complicit in the creation of a flabby nation, weakened by the weight of its own [large, but less than full] citizens. In these ways, their bodies and behaviour become "legitimate' targets of social sanction...' (Donaghue \& Clemitshaw 2012: 416) and it should be recognised that the so called 'war against obesity' is as much a war against fat individuals as it is a war against fat (Monaghan 2008:2 c/f Herndon 2005). Whilst Grosz (1994:19) identifies 'the white, youthful, able, male body...' as the dominant Western ideal, we must now surely also add, of 'normal' size, to that list. Any divergence from the normative (including ideal body size) has the effect of limiting the extent to which individuals or groups can act as empowered citizens in society and their ability to occupy more satisfying subject positions (Lorraine 2011).

\section{Deterritorializing Obesity Discourses}

3.1 My embodied experience as a white, middle aged, middle class? woman (all ways in which my identity has been organised) whose body weight has fluctuated for over three decades is enacted within and against the congealed assemblages of fat outlined above. Such territorializing discourses, however, have not gone unchallenged. Academic work across the disciplines has provided critical analyses of the nature of this 'war against obesity' and those that benefit and suffer from its ubiquitous promulgation in public policy and the media (Gard \& Wright 2005; Lupton 2012; Monaghan et al 2010; Rail 2012). This oppositional work aims to unpick the key premises on which contemporary obesity discourses are founded. Drawing on Rail's (2012:230-239) series of postcards these can be summarised as follows: obesity is a disease which is directly related to health problems; it is directly related to lifestyle and is an individual's responsibility; to ward off a global obesity epidemic, individuals, particularly women and 'Unhealthy Others', must submit to the advice of experts and lose weight, thus improving health. These premises, however, can be shown to lack a solid evidence base (Rail 2012). Unpicking the claim that obesity is related to poor health, for example, reveals that the link is tenuous, 
potential risks are prone to exaggeration and consideration of the social determinants of health is frequently lacking (Monaghan 2005). Similarly, the simple equation - weight loss equals better health - can also be shown to be problematic, in that efforts to lose weight can have detrimental outcomes e.g. weight cycling, and eating disorders (Rail 2012). The stigma attached to obesity and the resulting self hatred also has health negating rather than health improving effects (Puhl \& Heuer 2009). As LeBesco (2011: 161) starkly notes, 'The problem is that the very policing of fatness on health grounds endangers the well being of fat people'. Such concerns lie at the heart of the Health at Every Size (HAES) movement, which seeks to promote health and wellbeing without a focus on weight loss and self and societal acceptance of body size diversity (Burgard 2009).

3.2 Beyond mainstream critiques academics have also presented insights into the lived experience of fatness and weight loss practices through autobiographical or autoethnographic writing (Glenn 2012; Johnson \& Eaves 2013; Longhurst 2012; Murray 2005; Owen 2012; Pausè 2012). These studies add to our understanding of fat embodiment, for as Owen (2012: 291) argues, 'While popular cultural messages and public policies concerning fatness are vital threads in the tapestry of fat experiences, so also are the physical, tangible, somatic realities of fat bodies moving through space and time'.

3.3 Through the adoption of a Deleuzoguattarian theoretical framework, and experimenting with some of their key concepts to move towards generating new, life affirming ways of thinking about and living with fat, this semi autoethnographic piece thus aims to make a contribution to the critical obesity literature, and particularly that which explores fat embodiment and weight loss practices. It is to the work and concepts of Deleuze and Guattari that we turn next.

\section{Deleuze and Guattari: becoming \& the BwO}

4.1 Academic approaches to theorising the body are riven with limiting dualisms, which often serve to close down rather than open up fruitful avenues of theoretical and empirical exploration (See Howson \& Inglis 2001). The work of Deleuze and Guattari attempts to addresses these thorny and entrenched dualisms by attending to the processes of becoming that take place between bodies and other material and non material objects and technologies etc. As a poststructuralist, Deleuze rejects philosophical approaches which posit a foundational being (for Deleuze there is 'no being or subject who experiences' (Stagoll 2010a: 289)) (emphasis in the original)), as to do so decreases rather than increases the productive nature of the 'power of life' (Colebrook 2002). 'Rather, for Deleuze, one's self must be conceived as a constantly changing assemblage of forces, an epiphenomenon arising from chance confluences of languages, organisms, societies, expectations, laws and so on' (Stagoll 2010b: 27). Ontological primacy therefore must be given toexperience (not as foundational as in phenomenology but as a fluid process of becoming) rather than the form of the being that experiences, for the latter is but an affect of the former.

4.2 The turn to affect in the social sciences and the humanities has productively blurred the boundaries between bodies and the world (Blackman 2012; Gregg and Seigworth 2010). The singular bounded body as the object of study is replaced by a focus on what Blackman (2012: 1) calls 'brain-body-world entanglements'. What then becomes of interest are the relations between bodies and other material and non-material objects and their capacity to affect and be affected in ways which create new possibilities for becoming. 'Beings' are conceived in terms of their static identity, as becomings, bodies are processes of transformation, 'never ceasing to become' (Coleman 2011: 150 c/f Deleuze and Guattari 1987: 277 (305)).

4.3 What Deleuze and Guattari (1987) offer therefore is a conceptualisation of the body, not as organised, or formed or stratified (Message 2010) but as a body of multiplicities, flows and intensities. Any sense of a stable identity relies on what Deleuze and Guattari term abody with organs. The body with organs, the organism, is the 'ordered' body constructed by political and social discourse, particularly, in the case of fat, biomedical discourse. As described by Protevi (2010: 200-1) the organism (or the molar body) is the emerging effect of unifying processes, which fix bodies in particular ways. The body without organs (BwO) is by contrast one which is more open; an experimenting active body alert to ways of forming creative connections (assemblages) with the world which increase its potential (Deleuze and Guattari 1987). We should note, however, that the BwO always contains the body with organs and vice-versa; they are not separate entities. Thus it is possible for the BwO to howl, "'They've made me an organism! They've wrongfully folded me! They've stolen my body!"' (Deleuze \& Guattari 1987: 176). It is argued here that biomedical discourse has played a significant part in 'wrongfully folding' and 'stealing' the fat body, closing down the potential multiplicities which would open it to the world and the possibility of becoming otherwise. 
The concept of becoming is central to Deleuzoguattarian philosophy, as this is the term they use to emphasise the potential of multiplicities (the fat female body being one such multiplicity) to coalesce otherwise, and the processual nature of their philosophy. Thus 'becoming' is a fluid process that has no beginning or no end.

A line of becoming is not defined by points that it connects, or by points that compose it; on the contrary, it passes between points, it comes up through the middle [...] a line of becoming has neither beginning nor end, departure nor arrival, origin nor destination [...] A line of becoming has only a middle (Deleuze \& Guattari 1987: 323) (emphasis in the original).

4.5 Becoming the BwO then is always a process, not a final destination. Thus, I am not suggesting that through my weight loss practices or in writing about them that I have become, or can become the BwO. Rather, I am trying to work in and through the in-between (the middle) of my lived experiences of fat and weight loss as a way of experimenting with what the work of Deleuze \& Guattari has to offer.

4.6 The concept of becoming also requires us to think about difference differently, a central concern of Deleuzian philosophy (Braidotti 2011). For, as Braidotti (2002: 3) argues, 'Accounting adequately for changes is a challenge that shakes up long-established habits of thought. Most persistent among those is the habit that consists in dealing with differences in pejorative terms, that is to say, to represent them negatively'. In valuing difference over identity Deleuze and Guattari (1987) focus on the body, not as a constrained or constraining force but as a multiplicity of forces, with the potential to enact transformations, metamorphoses and becomings. As such, Deleuze and Guattari (1987) are not concerned with what a body signifies, what a body is, but with what a body can do. What assemblages can it make with other bodies and other objects material and non material, technologies and processes?

4.7 In order to affect and be affected, to be able to subvert the existing order, however, the body must remain to some extent within that organising system. Or as Deleuze and Guattari (1987: 178) put it 'You have to keep enough of the organism for it to reform each dawn [...] You don't reach the BwO,... by wildly destratifying'. The BwO then moves in and out of moments of becoming, and the strength of Deleuze and Guattari's work lies not in the erasure of bodies and objects but in the focus on their 'betweenness'. As articulated by Grosz (1994):

In Deleuze and Guattari's work, subject and object can no longer be understood as discrete entities or binary opposites [...] Subject and object are series of flows, energies, movements, strata, segments, organs, intensities fragments capable of being linked together or severed in potentially infinite ways other than those which congeal them into identities (Grosz 1994: 167).

\section{The Biggest Loser Club: Fat \& becoming slim [mer]}

5.1 As a sociology lecturer teaching a module on the body in society, in sharing with students how fat female bodies are often perceived negatively I struggled to reconcile the anti-obesity discourses I talked about with my own embodied experience. I felt increasingly uncomfortable in my own skin. Acutely aware of the paradox of critiquing anti obesity discourses whilst at the same time desiring slimness, I nevertheless didn't experience my body as being one of potential, as a becoming, with a focus on what it could do; I experienced it as a body that needed cutting down to size.

For me, wanting to be considerably slimmer is not a new desire. I have either been on a diet, or thinking that I should be on a diet for the most part of three decades. These diets have ranged from the minor (no snacking on chocolate) to the major (following a 'healthy diet' as advised by health care professionals over a period of several months) and also included the faddy (the cabbage soup diet). All led to weight loss, but although every attempt was accompanied by the fervent hope that this time will be the time the excess fat was permanently shed, it would creep (or race) back on. As a yo-yo dieter for most of that time I wasn't so much actively resisting the widely circulating anti-obesity discourses, but rather failing to achieve long term conformity.

5.3 My engagement, at the beginning of 2012, with the Biggest Loser [Diet] Club was prompted perhaps by a period of minor illness which led to the discovery of a dangerously high blood pressure, necessitating medication, and dire warnings from my GP about the risk of stroke, heart attack and diabetes. According to my body mass index (BMI) I was morbidly obese, a categorisation bringing with it a litany of possible health related risks \& the potential for an early death. So the push to diet this time was partly about improving my health, but also about the desire to be a 'normal' size. I felt that attaining a 'normal' body size (from a biomedical perspective this is a BMI of between 20-25 but subjectively this was imagined as a body which would fit into size 14 clothes) would rid me of the negative assemblages (fat - lazy - undisciplined - morally suspect) attached to the fat body. 
This desire to be slim [mer] was an embodied desire. In talking of shopping trips to "'regular" clothes stores', ones which did not specifically cater for larger women, Longhurst (2011: 879) writes 'I hardly ever entered these stores without feeling like my body's lack of solidity, its folds and softness offended some of the retailers' and shoppers' sensibilities... This is not something one can know for sure but more a visceral feeling in the presence of others'. This visceral feeling (affect), the body 'dys-appearing' rather than receding into the background (Leder 1990), increasingly overshadowed my ability to make positive assemblages with others. My body size intruded into my every life, not in the sense of a physical pain, but an affective 'pain' that limited what my body could do. In striving towards a more 'normal' size it was not just the outside of my body that I hoped to change. Body work is as much about transforming the self as it is about transforming the body (recognising of course that the distinction is an artificial one). As Rose (2001: 18) argues 'Selfhood has become intrinsically somatic - ethical practices increasingly take the body as a key site for work on the self'. Not only would I be a slim[mer] person I would also be a 'better' person, achieving a fitness that is simultaneously corporeal and psychological, allowing a hitherto unattainable 'fitting in' in the world. It was with this desire to fit in that I signed up for the Biggest Loser (Diet) Club in January 2012.

5.5 The reality TV show The Biggest Loser (TBL), first aired by NBC in America (2004) is now a global phenomenon. Part of the contemporary makeover culture, Ouellette and Hay (2008: 473 c/f Rose 1996:45) argue that television programmes such as TBL provide 'life interventions' which seek to create good neo-liberal citizens; 'who do not need to be governed by others, but will govern themselves, master themselves, care for themselves'. The creation of this 'entrepreneurial self', the individual who 'freely' regulates her own conduct by choosing reflexively and 'correctly' from the proliferation of consumer goods and lifestyles offered by the market and informed by experts, is central to neo-liberal 'governance at a distance' (Miller and Rose 2008). For the obese individual, joining a commercial weight loss programmes such as TBL, is one of the choices offered by the obesity entrepreneurs (Monaghan et al 2010) through which they can freely but diligently regulate their dietary conduct, bringing control to their recalcitrant bodies. Whilst The Biggest Loser television show has been the subject of academic enquiry (e.g. Holland, Warwick Blood \& Thomas 2015) the associated commercial dieting programme, to the author's knowledge, has not. Clarke (2015), however, provides an interesting analysis, again from a governmentality perspective, of the online Weight Watchers? ProPoints programme, He outlines three ways in which 'government at a distance' is enacted in this online environment: through the promulgation of scientific expertise; regulating the conduct of dieters through increasing dietary awareness, and by providing tools which make food choices and weight loss visible (Clarke 2015: 664-669). In a similar way, The Biggest Loser (Diet) Club, a commercial offshoot of the reality programme, provides an online platform for the bio pedagogies of The Biggest Loser to be taken up by individuals in their own home. On the website in addition to the weekly menu and exercise plan there is also the facility to document food consumed and exercise taken daily. Weight loss (or gain) is charted and weekly feedback given on the nutritional content of the food consumed. A 'cut the fat chart' provides a visual demonstration of the fat lost (yellow fat blobs) and information given on the percentage of body weight lost. A weekly early morning email on a day of my choosing reminds me that today is 'weigh in' day. On joining the club, members are encouraged to post a 'before' photograph of themselves (see mine below), the promise of the 'after' image lurking in the shadows. The 'before' image, a visible marker of the start of the weight loss journey and against which the 'after' image can be evaluated (and if the programme is successful applauded), can also be read as part of the 'confessional practices' that Rail (2012: 235) argues the fat subject is 'encouraged to engage in. .. so that they can be rescued, rehabilitated, and saved'. 


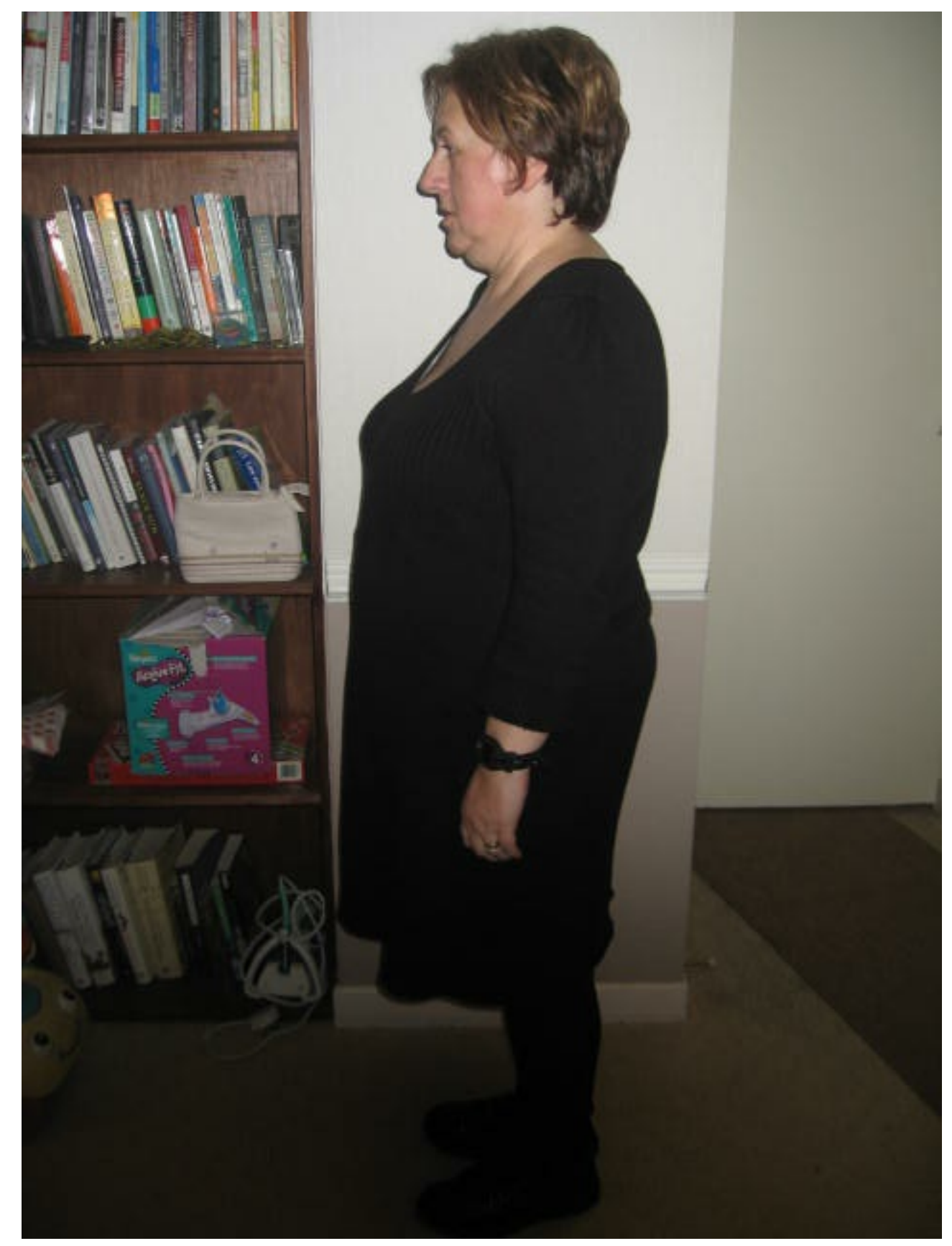

Figure 1. 'I am fat': Before picture (January 2012)

5.7 Adhering to the diet required willpower but this aspect was more familiar to me than the exercise plan.

Trying to complete the exercise programme (I had never heard of burpees) left me hot, sweaty, out of breath and often in tears. As a motivating incentive, I bought a heart rate monitoring device and borrowed an exercise bike. Weights and kettle bells followed. How many calories had I burnt off, what was my heart rate, how many hours of exercise had I completed that week? My body became a site of intense self surveillance and the effort to lose weight dominated my everyday life. I so wanted to be a 'good citizen'.

5.8 As the weight came off people started to comment positively on the changes, and often asked if I felt 'better in myself'. I am not sure if this question was addressed to any potential health benefits, an increased confidence or both. I found it disquieting that people were so affected by my weight. Was my body more forceful because it was becoming slimmer? Did this mean my fatter body was less forceful, or equally or more forceful, but in a negative way? An acquaintance commented that I looked 'dinky and petite', smaller in height as well as girth (cut down to size indeed). As time passed, people began to say 'You must be near your goal; I wouldn't lose any more weight if I were you'. Is this evidence that I have reached normality (although according to my BMI I have still some way to go?) When people I haven't met for some time say 'I didn't recognise you' what do they really mean?

\section{Belly Time: Fat, Mirrors and Becoming}


Thus far, I have discussed the ways in which obesity is currently territorialized in contemporary society and how this capture of the fat body affects women in particular. Key Deleuzoguattarian concepts have been introduced and my engagement with a commercial weight loss programme explored. In this section, through a deliberation of the ways in which adopting a Deleuzoguattarian perspective on becoming and time as advanced by Coleman $(2008,2011,2013)$ can usefully shed light on a specific aspect of my fat embodied experience, I continue to work towards this aim of 'free[ing] up the fixed relations that contain a body all the while exposing it to new organisations' (Parr 2010: 69). In revealing and probing the affective relationships I have with a particular body part, I am taking a stance (however tentatively) against those discourses which would have us believe that fat is shameful.

6.2 Although I can see the effects of the weight loss on my body and on my face, unlike some others, I have no difficulty in recognising myself. The loss of weight or exercise regime did not bring about the return of the body I had in my twenties. My fat body has only partially escaped from the slimmer one. One particular body part, my belly, was and remains a particular source of dissatisfaction. Whilst pregnancy was perhaps a time when I could happily 'eat for two' and my body become a site of pleasure rather than disgust, this was, by its very nature, a time limited experience. Even these positive pregnant body experiences were shadowed by concerns about the difficulties of losing the weight once the baby was born. Each pregnancy, whether resulting in the birth of a live child, or ending in loss (Sheach Leith 2009), left bodily traces - pounds (stones) of weight, silvery pink stretch marks and a fat, flabby belly. More than just excess flesh, it is also an embodied reminder of my reproductive successes and failures.

6.3 Partially clothed I stand facing a full length mirror and scrutinize my body. How do I look? Fatter, thinner, flabbier, firmer, better, worse, the same, normal? After this initial appraising and normalising gaze I proceed to grasp and manipulate the fat and flesh of my arms, my thighs, but particularly my belly into what contemporary culture presents to me as more acceptable, aesthetically pleasing shapes and forms. I stand taller, take a deep breath and pull my belly in, lift the loose skin, fold it in on itself and hold it together, undertaking a bloodless and temporary tummy tuck, a flat bellied imagining that unravels as I let go and that dimpled, overstretched skin and overhang returns to its usual position. Repeat tummy tuck, turn to the left, turn to the right, how do I look, how do I feel?

6.4 In forming an assemblage with the mirror, I engage in an embodied becoming that brings the future into the present, and the past into the present and the future. The 'imperative of transformation' a constitutive feature of contemporary society means that we are increasingly being required to think about and bring about the future in the present (Coleman 2013). Dietary practices informed by the biomedical framing of risk are of course one aspect of this temporal shift in which imagined futures (obesity morbidities) come to shape (be in) the present. What I see in the mirror then is not a static image, but rather 'What one has done and been, what is and what one could and should be, are all at once reflected in the body of the mirror. The mirror shows multiple temporalities simultaneously...' (Coleman 2013: 50). From a Deleuzian perspective the relationship (assemblage) between my body and the mirror is not one of a coming together of two separate entities. I do not see myself in the mirror nor does the mirror reflect myself to me, but both the mirror and myself (my body) become in the process of standing in front of the mirror. As Coleman f011: 152) argues, 'the theme of (self-) transformation works through a logic whereby bodies and images are not separate things but are in constitutive relations'.

6.5 Through forming an assemblage with the insights offered by Coleman's $(2008,2011,2013)$ work, I have come to see my belly as (and indeed my whole body) as a material and affective 'thing that stays'. Coleman (2008: 87) argues that, 'things that stay can be understood as durations; intense moments of the past which endure and which assemble with present and future temporalities'. This brings the past into the present and the future, 'Enduring things are not what a body has lived through but what a body is living (through) as non-linear durations' (emphasis in the original) (Coleman 2008: 93) For me, my belly is the central conduit through which past, present and future experiences and affects circulate and coalesce. It would seem then, that my attempts to excise (literally or metaphorically) the past are misguided. A more productive becoming can only be achieved by recognising the presence of the past in the now, and using this to create new ways of being affected by it in this moment and in the future (by creating, in other words, new belly becomings).

6.6 In an effort to create a new positive becoming for my belly (a 'belly without organs') in an earlier version of this paper presented at the 14th Annual International PEALS Spring Symposium in 2013, at the University of Newcastle (Privileged Embodiments: Securing and Resisting the 'Valuable' Body') I took what felt like a brave step away from molar thinking and presented an image of my hand gripping the large roll of fat that is my 
abdomen. The taking of this photograph was inspired by reading Maioli's (2010) discussion of Jenny Saville's paintings of very fat women, and the painting Branded (Jenny Saville 1992). In the presentation I covered the image with the quotation from Maioli (2010) below, which had the effect of partially obscuring the image (this was perhaps not entirely unintended).

The woman's hand gripping a roll of fat, in fact, can be interpreted both as a synecdoche for a woman who looks at herself through the mirror in self-disgust and one whose self-exhibited nakedness is an attempt to defy cultural standards (Maioli 2010: 80).

6.7 Members of the audience commented that obscuring the image in this way served to negate the impact of the image, reducing its capacity to affect. Would presenting the image in this article unadorned be a further step to opening up my perceptions of my belly to becoming otherwise? Or would presenting that image to a much larger audience be seen as unwise, as taking 'navel gazing' too far? I vacillate: insert/cut the jpeg image (repeat). Cut.

\title{
Discussion: Embodied, theoretical and ethical 'lines of flight'
}

7.1 In the above I have sought to use my own embodied experience of fat and weight loss as a way of experimenting with Deleuze \& Guattari's work. In this penultimate section I reflect on the potential of their work for thinking about fat differently through a consideration of embodied, theoretical and ethical lines of flight. A line of flight can be understood as a form of deterritorialization, cutting across molar forms of thinking and being which constrain potential becomings to free 'new powers in the capacities of... bodies to act and respond' (Lorraine 2010: 147). Dettorialization throws stable identities back into the flux of difference from which new becomings can emerge. A line of flight thus opens up new ways of becoming, thinking, working; creating new and productive assemblages/connections. Whilst aware that the distinction is an artificial one, in what follows, for purposes of clarity, I focus on embodied, theoretical and ethical lines of flight separately.

\section{Embodied lines of flight: What can a [my] body do?}

\begin{abstract}
We know nothing about a body until we know what it can do, in other words, what its affects are, how they can or cannot enter into composition with other affects, with the affects on another body either to destroy that body, or to be destroyed by it, either to exchange actions and passions with it or to join with it in composing a more powerful body (Deleuze \& Guattari 1987: 284).
\end{abstract}

8.1 In reflecting on my embodied experience it is useful to think in terms of 'what can [my] body do'. Fox (2002: 356) argues that shifting the focus from what a bodyis to '[a]sking what can a body do', 'recognizes an active, experimenting, engaged and engaging body, not one passively written in systems of thought. Bodies are not the locus at which forces act, they are the production of the interaction of forces', and ends by quoting from Buchanan (1997: 83) who states that, 'A body isthe capacity to form new relations, and the desire to do so ...;' (Italics in Fox 2002: 356).

8.2 In terms of what my body can do, it now has the capacity to form novel assemblages with exercise and the outdoors. The ability to do things that were hitherto if not impossible, but certainly less achievable (or even desirable), such as occasional hill walking feels joyful and this more productive assemblage with the outdoors has led to a new and incredibly satisfying interest in bird watching (to new desires in other words). A self defined increase in overall fitness and the appearance of muscles on my thighs and arms is experienced at times as a feeling of power (an opening out my embodied potential) and I am no longer tied by molar forms of thought (including my own) to the armchair. On good days (when the past, present and the future intensify in pleasurable/joyful ways) multiple lines of flight seem possible. In terms of benefits to my health that are more open to measurement, yes, my blood pressure is now within 'normal' parameters. Yet, justified through the language of risk, as 'someone who once had high blood pressure', I continue to be called for screening at the cardiovascular clinic.

8.3 Attending to my body then, in a way which could be conceptualised as forming assemblages with the molar discourses of obesity, has had multiple effects and affects. 'Becoming other requires the multiplication of affects, not the intensification of a single affect or relation. It is an opening-up to difference, to possibility and to the 'rightness' of the many rather than the few or the one' (Fox 2002: 359). Such lines of flight and ways of becoming are however still nascent (nor would their fixing be desirable) and molar thinking and ways of being continue to have a strong pull. The assemblages I create with food remain problematic; it is never just neutral fuel, but 'good' food or 'bad' food. Thinking about my weight, about losing weight, being fearful of putting on weight are aspects of my everyday life that colour my perceptions of self and my engagement with the world in ways which could not be seen as deterritorializing. The BwO is however always a becoming, not an end point. 


\section{Theoretical lines of flight: Bodies, becoming \& time}

9.1 Rethinking how we can live, as Deleuze and Guattari enjoin us to do, requires that we think differently also (I am not returning to Cartesian Dualism here, as like the body and the mirror, the mind and the body are not separate but assemblages of forces). Throughout this paper the body and time have played a key part. How might Deleuze \& Guattari assist in efforts to think differently about both? Analyses of weight loss practices have tended to focus on participants as beings, who are organised \& folded into 'docile bodies' through bio power. More recently there has been greater attention paid to the embodied experiences of participants. Such a shift in perspective recognises that whilst emphasising autonomous agency in relation to such disciplining 'body practices' is problematic, that participants can create new and positive ways of becoming otherwise which are experienced as empowering. Adopting a Foucauldian perspective to interrogate her engagement with Weight Watchers, as Heyes (2007) notes,

\footnotetext{
On the one hand, deliberately losing weight by controlling diet involves the self- construction of a docile body through attention to the minutest detail. On the other hand, becoming aware of exactly how and what one eats and drinks, realizing that changing old patterns can have embodied effects, or setting a goal and moving toward it, are all enabling acts of self-transformation (2007: 67).
}

This tension between my enthusiastic engagement with the disciplining practices of the Biggest Loser Diet Club, and the assemblages of positive self transformation discussed in the previous section is clearly evident in this article. Does losing pounds mean that I have capitulated to the biomedical discourses outlined in the introduction in a way which diminishes my ability to take a critical stance towards current obesity discourses? This tension has been explored by a number of feminist academics, including Bordo (2003). Reflexively discussing her own decision to lose weight in 1990, she highlights the complexity of that choice, viewed by some of her colleagues as 'inconsistent and even hypocritical' (Bordo 2003: 30) given her feminist stance. Women, Bordo (2003: 30) argues are not 'cultural dopes' for pursing the 'choices' offered by contemporary culture, but neither are they exercising a wholly free choice. Indeed, whilst she highlights the importance of making the 'systemic nature of culture' visible through consciousness raising and recognises the autonomy of the individual to utilise that knowledge in their own lives, she also reflects that the positive personal affects of her weight loss should not lead her to believe that she is not maintaining a system of oppression (Bordo 2003: 30-31). In more recent work, Longhurst (2012: 884) similarly grapples with the paradox inherent in critiquing obesity discourses whilst at the same time desiring slimness, commenting that 'since losing weight I have at times felt uncomfortable that... I am reproducing dominant ways of knowing and being that construct my slimmer subjectivity at the expense of those who are constructed as fat Others (and a future fat self).' Even frameworks which would seem to present alternatives can be viewed as problematic. Samantha Murray (2005) talks about the tensions involved in the model of embodiment inherent in the fat acceptance movement, which in proposing learning to love yourself, privileges mind over body. Murray (2005: 161) argues that this model undermines 'it's celebration of the fat body' by asking 'fat women to occupy positions outside our [their] bodies'. The disavowal of fat continues, and Donaghue \& Clemitshaw (2012) in studying the subjective experiences of women taking part in an online fat acceptance blog, note the ambiguity and complexity women face when trying to create more positive subjectivities for themselves. The pull of the dominant "thin' is good discourse' is very strong and the title of their paper 'I'm totally smart and a feminist and yet I want to be a waif' encapsulates such dilemmas well.

9.3 To be sure, some of this feeling of empowerment outlined above comes from having a body which is now seen as more acceptable in contemporary society. Whilst this recognition in itself does not erase this paradox, as Bordo (2003: 30-31) argues in the context of her work 'Feminist cultural criticism cannot magically lift us into a transcendent realm of immunity to cultural images, but it ought to help guard against the feeling of comfortable oneness with culture and to foster a healthy scepticism about the pleasures and powers it offers'. Perhaps adopting a Deleuzoguattarian perspective to think about the embodied practices of weight loss, and the potential assemblages resulting from those practices, offers a way of thinking (and living) through this paradox which places greater emphasis on the fruitful becomings that can arise from becoming slimmer, whilst remaining critical and engaging with obesity discourses. Becoming slim is not the goal, the goal is becoming.

9.4 Whilst in this paper I have paradoxically utilised my weight loss as a way of experimenting with Deleuze and Guattari's work in an effort to deterritorialize fat, other body projects which do not involve weight loss could be similarly explored. Indeed, in exploring fat in the context of Marathon swimming (where fat insulates against the cold), whilst Karen Throsby (2015: 780) failed to find a space in which fat shed its negative connotations entirely, in that context nevertheless 'the unexpected freedoms of guilt-free consumption, the pleasures of bodily solidity and the liberation from shame-filled daily encounters with scales all signal a re-orientation, however ambivalent, towards fat...'. 
The opportunity to think about time differently is another significant theoretical becoming that engaging with Deleuze offers. Whilst temporality in the West is traditionally conceptualised in a linear fashion; past, present, future, in drawing on Bergson's work, Deleuze, rethinks linear conceptions of time. As May (2003: 145) writes of Bergson 'When time is conceived as a whole, each of its instants is internally related to every other instant. The past is connected to the present (and the future), but not connected as something that is no longer exists to something that does exist (or will)'. As we have seen Deleuzian insights into time as a multiplicity has been used by Coleman (2013) to theorise how the imperative of transformation brings the future into the present. Loewen Walker (2014: 54) has also taken up the challenge to think differently about time, and in creating assemblages between feminist materialism(s) and Deleuze has developed the concept of the living present to encapsulate time as a becoming rather than a static 'now', 'the time that we may experience as present is always a stretching between past and future, as it contracts those experiences that contribute to the sense of the moment and expects those yet to come' (emphasis in the original). The past then is not something that is lost, or should be lost, but something which is (re)imagined in the now and in the future. Rethinking time in this way could open up new possibilities for research into the embodied experience of weight and weight loss/gain, and shed new light on how health promotion messages and practices might engage with those experiences in a way which recognises and increases the fat body's potential for a becoming. Although not adopting a Deleuzoguattarian perspective, the potential of such research is reflected in work by Bomback (2015:2), who highlights the need to consider temporality in understanding '[e]mbodied weight histories' and also Glenn (2012), who draws attention to the effects of 'waiting on weight loss' on lived experience. Both authors call for greater attention to be paid to these temporal aspects of weight loss/weight gain in the shaping of clinical practice. Doing so, it is argued, would facilitate encounters between obese individuals and health care professionals, which take into account their 'experiential knowledge, struggles and priorities' (Bomback 2015: 12) and thus 'bring about a more tactful encounter with the other' (Glenn 2012: 357), which need not focus narrowly on weight loss.

\section{Ethical lines of flight: becoming ethical}

10.1 As has been indicated throughout the above, Deleuzoguattarian philosophy is concerned with offering a way of engaging with the world in which our power of acting is increased, through facilitating the creation of multiple assemblages and an opening out our ability to affect and be affected (Duff 2014). At the outset of this article I sought to demonstrate how current molar thinking about fat, including biomedicine had the effect of limiting the lines of flight available to fat bodies, restricting their power of acting. In discussing my own experiences I have, it is hoped, stimulated ways of thinking differently about fat and weight loss, which open up rather than close down ways of becoming. Overall, it could be argued that to deterritorialize the current stigmatizing assemblages of fat and the molar identities they propagate requires a becoming ethical (in relation to oneself and others). Beyond the ethical relations with oneself, becoming ethical entails consideration of the opportunities offered by Deleuze \& Guattari's work to increase the power of acting of health care and health promotion practices in relation to fat bodies, but not, of course, in the sense of promoting greater efficacy or compliance.

10.2 Cameron Duff's (2014) work is particularly valuable in suggesting a way forward which increases our ability to think differently about health. Duff (2014: 176) argues that the 'will to health' in contemporary neo-liberal society is suffused with moral judgements, and that 'health must be converted from a moral into an ethical consideration'. Thinking ethically about health requires 'an evaluation of what bodies "can do" in their encounters with one another- and not as an effect of the observance of particular principles or rules' (Duff 2014: 153). From this perspective health (and illness) is not something which inheres in individual bodies but is 'a function of encounters' and Duff (2014: 176) goes on to suggest that 'both the promotion of health, and recovery from illness, necessitate the identification of affects, relations, events, bodies, forces, spaces and signs that enable a body to maintain or recuperate its strength, reason or freedom in real experience'. The concepts of strength, reason or freedom are expounded at length by Duff (2014) but here, for the purposes of brevity, they can be understood as an increase in our (individual and collective) power of acting. Whilst this article sought in part to demonstrate how my engagement with assemblages of health (diet and exercise) has served to increase my own power of acting, Duff's (2014) work can be read as a challenge to the social sciences to form an assemblage with Deleuze \& Guattari and to apply their work to the world of experience in relation to health care. Duff (2014) provides two examples (mental health recovery and drug use) of how this might be done, but the need for new insights and empirical work is equally as pressing in relation to assemblages of fat and fat bodies.

\section{Conclusion}

11.1 In this article I have sought to interrogate my own embodied experience of fat and weight loss as a becoming with the aim of demonstrating some of the potential offered by Deleuze and Guattari's work, for living 
with and thinking about fat differently. Thinking through bodies, their multiplicities and positive capacities (their active becomings) in such a way, I argue, can open up new spaces to live with and connect with bodies that are currently stratified as fat, bodies (including my own) which have been 'wrongfully folded' and essentially stolen. When bodies are viewed predominately through a moral lens their capacities are closed down rather than opened up. In creating an embodied and theoretical assemblage with my own body as a becoming this article may be seen as a small step towards deterritorializing the current moral and molar thinking surrounding fat. By taking up Deleuze and Guattari's challenge to think (and live) differently, it is argued that fat (female) bodies can be facilitated to increase their power of acting in the living present and to never cease to become the BwO.

\section{Acknowledgements}

I would like to thank the anonymous reviewers for their constructive feedback and Lucia Ruggerone at Robert Gordon University for her valuable input and encouragement.

\section{References}

BLACKMAN, L (2012) Immaterial Bodies: Affect, Embodiment, Mediation. London: Sage Publications Ltd. [doi:10.4135/9781446288153]

BOMBACK, A. E (2015) 'Obesities': Experiences and perspectives across weight trajectories.Health Sociology Review, Vol. 24, No.3, p. 256-269. [doi:10.1080/14461242.2015.1045919]

BORDO, S. (2003) Unbearable Weight: Feminism, Western Culture, and the Body(Tenth Edition), London: University of California Press, Ltd.

BRAIDOTTI, R (2002) Metamorphoses: Towards A Materialist Theory Of Becoming Cambridge: Polity Press.

BRAIDOTTI, R (2011) Nomadic Subjects: embodiment and sexual difference in contemporary feminist theory (Second Edition). New York: Columbia University Press.

BUCHANAN, I (1997) The Problem of the Body in Deleuze and Guattari, Or, What Can a Body Do?Body \& Society, Vol. 3, No. 3, p. 73-91. [doi:10.1177/1357034X97003003004]

BURGARD, D (2009) What is 'Health at Every Size'? In Rothblum, E \& Solovay, S (2009) (Eds.)The Fat Studies Reader. New York \& London, New York University Press.

CLARKE, A (2015) Governing the dieting self: Conducting weight-loss via the internet.Journal of Sociology, Vol. 15, No. 3, p. 657-673. [doi:10.1177/1440783314522869]

COLEBROOK, C (2002) Gilles Deleuze (Routledge Critical Thinkers). London: Routledge.

COLEMAN, R (2008) 'Things That Stay': Feminist theory, duration and the future. Time \& Society, Vol. 17, No. 1, p. 85-102. [doi:10.1177/0961463X07086303]

COLEMAN, R (2011) 'Be(come) Yourself only Better': Self-transformation and the Materialisation of Images. In Guillaume, L \& Hughes, J. (Eds.) Deleuze and the Body, Edinburgh: Edinburgh University Press. [doi:10.3366/edinburgh/9780748638642.003.0007]

COLEMAN, R (2013) Transforming Images: Screens, affect, futures. London and New York: Sage Publications.

DELEUZE, G \& GUATTARI, F (1987)A Thousand Plateaus: Capitalism and Schizophrenia.London: Continuum International Publishing Group.

DONAGHUE, N \& CLEMITSHAW, A (2012) 'I'm totally smart and a feminist...and yet I want to be a waif': Exploring ambivalence towards the thin ideal within the fat acceptance movement, Women's Studies International Forum, Vol. 35, p. 415-425. [doi:10.1016/j.wsif.2012.07.005]

DUFF, C (2014) Assemblages of Health: Deleuze's Empiricism and the Ethology of Life. Dordrecht: Springer. 
FOX, N.J (2002) Refracting 'Health': Deleuze, Guattari and Body-Self, Health: An Interdisciplinary Journal for the Social Study of Health, IIIness and Medicine, Vol. 6, No. 3, p. 347-363.

[doi:10.1177/136345930200600306]

GARD, M \& WRIGHT, J (2005) The Obesity Epidemic: Science, Morality and Ideology. London and New York: Routledge.

GLENN, N. M (2012) Weight-ing: The Experience of Waiting on Weight Loss,Qualitative Health Research, Vol. 23, No. 3, p. 348-360. [doi:10.1177/1049732312468795]

GREGG, M \& SIEGWORTH, G, J (2010) An Inventory of Shimmers, In GREGG, M \& SIEGWORTH, G, J (2010) (Eds) The Affect Theory Reader, Durham \& London: Duke University Press.

GROSZ, E (1994) Volatile Bodies: Toward a Corporeal Feminism. Bloomington: Indiana University Press.

HEYES, C. J (2007) Self-Transformations: Foucault, Ethics and Normalized Bodies. Oxford: Oxford University Press. [doi:10.1093/acprof:oso/9780195310535.001.0001]

HOLLAND, K., BLOOD, R \& THOMAS, S (2015) Viewing The Biggest Loser: modes of reception and reflexivity among obese people. Social Semiotics, Vol. 25, No. 1, p. 16-32. [doi:10.1080/10350330.2014.955980]

HOWSON, A \& INGLIS, D (2001) The body in sociology: tensions inside and outside sociological thought. Sociological Review, Vol. 49, No. 3, p. 297-317. [doi:10.1111/1467-954x.00333]

JOHNSON, C. R.S \& EAVES, K. L (2013) An ounce of time, a pound of responsibilities and a ton of weight to lose: An autoethnographic journey of barriers, message adherence and the weight-loss process. Public Relations Inquiry, Vol.2, No.1, p. 95-116. [doi:10.1177/2046147X12460949]

KRISTEVA, J (1982) Powers of Horror: An Essay on Abjection New York: Columbia University Press.

LEBESCO, K (2011) Neoliberalism, public health, and the moral perils of fatness, Critical Public Health, Vol.21, No. 2, p.153-164. [doi:10.1080/09581596.2010.529422]

LEDER, D (1990) The Absent Body. Chicago: The University of Chicago Press.

LOEWEN WALKER, R (2014) The Living Present as a Materialist Feminist Temporality, Women: A Cultural Review, Vol. 25, No. 1, p. 46-61. [doi:10.1080/09574042.2014.901107]

LONGHURST, R (2012) Becoming Smaller: Autobiographical Spaces of Weight Loss,Antipode, Vol. 44, No. 3, p. 871-888. [doi:10.1111/j.1467-8330.2011.00895.x]

LORRAINE, T (2010) Lines of Flight. In Parr, A. (Ed.) The Deleuze Dictionary: Revised Edition. Edinburgh: Edinburgh University Press Ltd.

LORRAINE, T (2011) Deleuze and guattari's immanent ethics: theory, subjectivity and duration. Albany: State University of New York.

LUPTON, D (2012) Fat. London: Routledge.

MAIOLI F (2010) Nomadic Subjects on Canvas: Hybridity in Jenny Saville's PaintingsWomen's Studies, Vol. 40, No.1, p. 70-92. [doi:10.1080/00497878.2011.527795]

MAY, T (2003) When is a Deleuzian becoming? Continental Philosophy Review, Vol. 36, p. 139-153. [doi:10.1023/A:1026036516963]

MCNAUGHTON, D (2011) From the womb to the tomb: obesity and maternal responsibility, Critical Public Health, Vol. 21. No. 2, p. 179-190. [doi:10.1080/09581596.2010.523680]

MESSAGE, K (2010) Body Without Organs. In PARR, A (2010) (Ed.) The Deleuze Dictionary. Revised Edition, Edinburgh: Edinburgh University Press.

MILLER, P \& ROSE, N (2008) Governing the Present. Administering Economic, Social and Personal Life. Cambridge: Polity Press. 
MONAGHAN, L. F (2005) Discussion Piece: A Critical Take on the Obesity Debate,Social Theory \& Health, Vol. 3, No. 4, p. 302-314. [doi:10.1057/palgrave.sth.8700058]

MONAGHAN, L. F (2008) Men and the War on Obesity: A Sociological Study. London \& New York: Routledge.

MONAGHAN, L. F., HOLLANDS, R \& PRITCHARD G (2010) Obesity Epidemic Entrepreneurs: Types, Practices and Interests, Body \& Society, Vol.16, No. 2, p. 37-71. [doi:10.1177/1357034X10364769]

MURRAY, S (2005) (Un/Be) Coming Out? Rethinking Fat Politics,Social Semiotics, Vol. 15, No.2, p. 153-163. [doi:10.1080/10350330500154667]

OUELLETTE, L \& HAY, J (2008) Makeover television, governmentality and the good citizen.Continuum: Journal of Media \& Cultural Studies, Vol. 22, No. 4, p. 471:484.

OWEN, L (2012) Living fat in a thin-centric world: Effects of spatial discrimination on fat bodies and selves. Feminism \& Psychology, Vol.22, No.3, p. 290-306. [doi:10.1177/0959353512445360]

PARR, A (2010) (Ed) The Deleuze Dictionary. Revised Edition, Edinburgh: Edinburgh University Press Ltd.

PAUSÉ, C (2012) Live to Tell: Coming Out as Fat, Somatechnics, Vol.2, No. 1, p. 42-56. [doi:10.3366/soma.2012.0038]

PROTEVI, J (2010) Organism. In Parr, A. (Ed.) The Deleuze Dictionary: Revised Edition. Edinburgh: Edinburgh University Press Ltd.

PUHL, R. M. \& HEUER, C.A (2009) The Stigma of Obesity: A Review and Update,Obesity, Vol. 17, No. 5, p. 941-964. [doi:10.1038/oby.2008.636]

RAIL, G (2012) The Birth of the Obesity Clinic: Confessions of the Flesh, Biopedagogies and Physical Culture, Sociology of Sport Journal, Vol. 29, p. 227-253. [doi:10.1123/ssj.29.2.227]

ROSE, N (2001) The Politics of Life Itself, Theory, Culture \& Society, Vol. 18, No. 6, p. 1-30. [doi:10.1177/02632760122052020]

SHEACH LEITH, V. M (2009) The Search for Meaning after Pregnancy Loss: An Autoethnography, IIIness, Crisis and Loss, Vol. 17, No. 3, p. 201-221.

SHILDRICK, M (1997) Leaky Bodies and Boundaries: Feminism, Postmodernism And (Bio)ethics, London: Routledge.

SHILDRICK, M (2002) Embodying the Monster. Encounters with the Vulnerable Self, London: Sage Publications.

SKEGGS, B (1997) Formations of Class and Gender. Becoming Respectable. London: Sage Publications.

STAGOLL, C (2010a) Transcendental Empiricism. In Parr, A. (Ed.) The Deleuze Dictionary: Revised Edition. Edinburgh: Edinburgh University Press Ltd.

STAGOLL, C (2010b) Becoming. In Parr, A. (Ed.) The Deleuze Dictionary: Revised Edition. Edinburgh: Edinburgh University Press Ltd.

THROSBY, K (2015) 'You can't be too vain to gain if you want to swim the Channel': Marathon swimming and the construction of heroic fatness, International Review for the Sociology of Sport Vol. 50, No.7, p. 769-784. [doi:10.1177/1012690213494080]

TURNER, B.S (2008) The Body \& Society (Third Edition). London: Sage Publications Ltd. 